\title{
The Time Course of Changes in Motor Cortex Excitability Associated with Voluntary Movement
}

\author{
Robert Chen and Mark Hallett
}

\begin{abstract}
The excitability of the motor cortex is modulated before and after voluntary movements. Transcranial magnetic stimulation studies showed increased corticospinal excitability from about 80 and $100 \mathrm{~ms}$ before EMG onset for simple reaction time and self-paced movements, respectively. Following voluntary movements, there are two phases of increased corticospinal excitability from 0 to approximately $100 \mathrm{~ms}$ and from approximately 100 to $160 \mathrm{~ms}$ after EMG offset. The first phase may correspond to the frontal peak of motor potential in movement-related cortical potentials studies and the movement-evoked magnetic field I (MEFI) in magnetoencephalographic (MEG) studies, and likely represents a time when decreasing output from the motor cortex falls below that required for activation of spinal motoneurons, but is still above resting levels. The second phase of increased corticospinal excitability may be due to peripheral proprioceptive inputs or may be centrally programmed representing a subthreshold, second agonist burst. This may correspond to the MEFII in MEG studies. Corticospinal excitability was reduced below baseline levels from about 500 to 1,000 ms after EMG offset, similar to the timing of increase in the power (event-related synchronization, ERS) of motor cortical rhythm. Similarly, motor cortex excitability is reduced at the time of ERS of motor cortical rhythm following median nerve stimulation. These findings support the hypothesis that ERS represents an inactive, idling state of the cortex. The time course of cortical activation is abnormal in movement disorders such as Parkinson's disease and dystonia, reflecting abnormalities in both movement preparation and in cortical excitability following movement.
\end{abstract}

RÉSUMÉ: Évolution dans le temps des changements de l'excitabilité du cortex moteur associée au mouvement volontaire. L'excitabilité du cortex moteur est modulée avant et après les mouvements volontaires. Des études de stimulation magnétique transcrânienne ont montré une augmentation de l'excitabilité corticospinale précédant de 80 et $100 \mathrm{~ms}$ le début de la réponse ÉMG pour le temps de réaction simple et l'activité motrice autocommandée respectivement. Après un mouvement volontaire, il y a deux phases d'excitabilité corticospinale accrue de 0 à approximativement 100 ms et d'approximativement 100 à $160 \mathrm{~ms}$ après la fin de la réponse ÉMG. La première phase peut correspondre au pic frontal du potentiel moteur dans les études de potentiels corticaux reliés aux mouvements et le champ magnétique I évoqué par le mouvement (MEFI) dans les études magnétoencéphalographiques (MEG), et représente vraisemblablement un moment où l'influx nerveux du cortex moteur tombe sous le niveau requis pour l'activation des motoneurones spinaux, mais demeure au-dessus du niveau observé au repos. La deuxième phase d'augmentation de l'excitabilité corticospinale peut être due à des influx proprioceptifs périphériques ou peut être programmée centralement, représentant une poussée agoniste secondaire sous le seuil. Ceci peut correspondre au MEFII dans les études MEG. L'excitabilité corticospinale était diminuée sous le niveau de base d'environ 500 à 1,000 ms après la fin de la réponse ÉMG, comme au moment de l'augmentation de la puissance (synchronisation reliée à l'événement, SRE) du rythme cortical moteur. Pareillement, l'excitabilité du cortex moteur est diminuée au moment des SRE du rythme cortical moteur après une stimulation du nerf médian. Ces observations supportent l'hypothèse que la SRE représente le cortex à l'état inactif. Le processus de l'activation corticale est anormal dans les désordres du mouvement tels la maladie de Parkinson et la dystonie, ce qui témoigne d'anomalies dans la préparation du mouvement et dans l'excitabilité corticale après le mouvement.

Can. J. Neurol. Sci. 1999; 26: 163-169

Since Hughlings Jackson's observation of the focal onset and subsequent spread of motor seizures ${ }^{1}$ and the early electrical stimulation studies of Sherrington and Penfield, ${ }^{2,3}$ the motor cortex has been considered to play a central role in movement execution. More recently, there is also evidence that motor cortex excitability is modulated before and after voluntary movement. Recordings from the monkey motor cortex showed increased neuronal activity beginning 70 to $100 \mathrm{~ms}$ before movement onset, and the firing rate progressively increases up to the time of movement onset. ${ }^{4-7}$ After cessation of movement, many motor cortex neurons also continue to discharge above baseline levels. ${ }^{4,8,9}$

In humans, activity of the motor cortex can be studied non- invasively with neuroimaging or physiological techniques. However, neuroimaging techniques such as positron emission tomography and functional magnetic resonance imaging do not have adequate temporal resolution to reveal the detailed time course of cortical activation. Therefore, most of the current

From the Division of Neurology, University Health Network and University of Toronto, Toronto (R.C.); and the Human Motor Control Section, National Institutes of Neurological Disorders and Stroke, National Institutes of Health, Bethesda, Maryland (M.H.).

RECEIVED JANUARY 19, 1999. ACCEPTED IN FINAL FORM APRIL 9, 1999.

Reprint requests to: Dr. Robert Chen, Toronto Western Hospital, University Health

Network, EC8-025, 399 Bathurst Street, Toronto, Ontario, Canada M5T 2 S8.

Presented, in part, as the Herbert Jasper Prize Lecture at the 33rd Meeting of the

Canadian Congress of Neurological Sciences, Montreal, Quebec, June 1998. 
information regarding the time course of changes in motor cortex excitability associated with voluntary movements comes from physiological studies, such as electroencephalography (EEG), magnetoencephalography (MEG), transcranial magnetic stimulation (TMS) or transcranial electrical stimulation (TES). We review here the time course of changes in motor cortex excitability before and after voluntary movements, and attempt to correlate the findings from different physiological techniques.

\section{Modulation of Motor Cortex Excitability Before VOLUNTARY MOVEMENT}

Changes in motor cortex excitability before voluntary movement can be studied with movement-related cortical potentials (MRCPs), movement-related magnetic fields (MRMFs), power changes of cortical rhythms recorded by EEG or MEG, and stimulation of the motor cortex by TMS or TES. We will discuss these studies separately.

Transcranial magnetic stimulation (TMS) and transcranial electrical stimulation (TES) studies

Several studies ${ }^{10-15}$ used TMS or TES to examine corticospinal excitability prior to movement onset in simple reaction time (RT) movements. In simple RT paradigms, the subject performs a predetermined simple movement, such as thumb abduction or wrist extension, as soon as possible after an external "go" signal, such as an auditory tone or a light flash. There is little time for movement preparation and the RT is usually about 200 ms. In these studies, the TMS or TES were adjusted to just subthreshold for producing motor-evoked potentials (MEPs) with the subject at rest. This produced a stable baseline and a minimal increase in corticospinal excitability led to recordable MEPs. These studies showed that corticospinal excitability begins to rise above baseline levels about $80 \mathrm{~ms}$ prior to EMG onset, and continues to increase up to the time of EMG onset (Figure 1). This premovement increased corticospinal excitability is likely related to the motor cortex itself, since its timing corresponds well with that of increased activity in the monkey motor cortex neurons prior to movement onset. ${ }^{4-7}$ Spinal reflexes are also facilitated from 50 to $100 \mathrm{~ms}$ before EMG onset in simple RT paradigms, ${ }^{16-18}$ indicating that there are also changes in the central commands to the spinal cord prior to movement. The changes in spinal reflexes are likely due to reduction in presynaptic inhibition rather than subthreshold activation of motoneurons. ${ }^{16-18}$ Thus, premovement increased excitability occurs at both cortical and spinal levels.

While simple RT paradigms represent a special laboratory situation, most of the movements people make are self-paced, in which the subject determines when the movement occurs. In order to examine changes in corticospinal excitability prior to self-paced movements, we studied self-paced movements with subjects performing thumb abductions about once every 4 to 5 seconds without external clues. ${ }^{15}$ The premovement increase in corticospinal excitability begins about $100 \mathrm{~ms}$ before EMG onset, about $20 \mathrm{~ms}$ earlier than that for simple RT movements (Figure 1). ${ }^{15}$ The difference between self-paced and simple RT movements was statistically significant. ${ }^{15}$ Our results suggested that in simple RT paradigm in which the subject was required to move as fast as possible, the rate of rise in corticospinal excitability can be increased, but only to a limited extent.

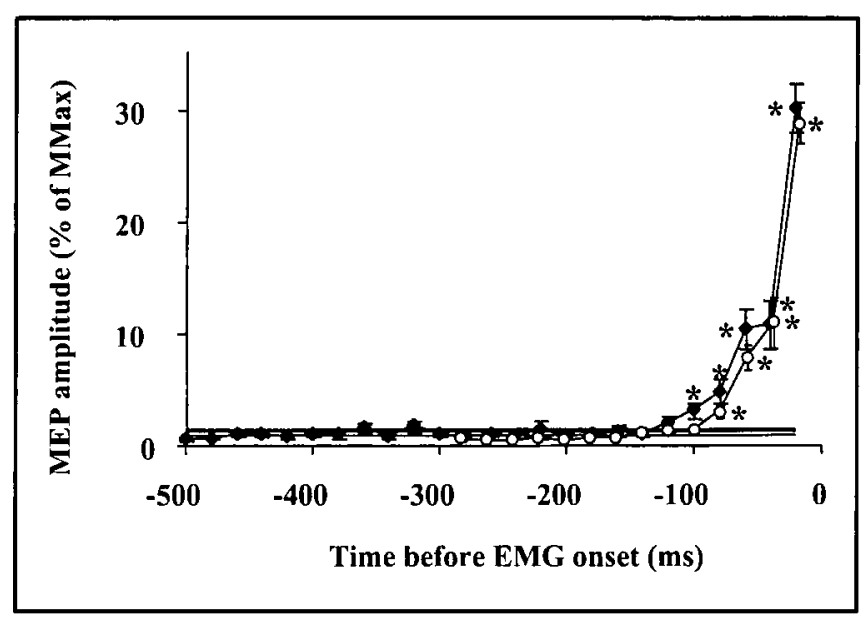

Figure 1: The time course of corticospinal excitability before voluntary movements. Results from six subjects who performed thumb abduction movements. Surface EMG was recorded from the abductor pollicis brevis muscle. Subthreshold transcranial magnetic stimulation was applied at different times before EMG onset. The open circles represent simple reaction time movements and the black diamonds represent self-paced movements. MEP amplitudes are expressed as percentages of the compound muscle action potential obtained by supramaximal stimulation of the median nerve at the wrist (MMax). Error bars represent $\pm S E M$. The horizontal lines represent mean $\pm S E M$ of the baseline and the asterisks represent significant difference from baseline (unpaired t test, $P<0.05$, after Bonferroni correction). The premovement increase in corticospinal excitability began significantly earlier $(p=0.03$, unpaired t test) for selfpaced movements $(-100 \mathrm{~ms})$ compared to simple reaction time move. ments $(-80 \mathrm{~ms})$. Modified from Chen et al. ${ }^{15}$

\section{Movement-related cortical potential (MRCP) studies}

In MRCP studies, scalp EEG or electrocorticographic (ECoG) recordings time-locked to movement onset are averaged. With self-paced movements, MRCPs recorded before movement onset may be divided into three components: the Bereitshaftspotential (BP) starting 1 to 2 seconds before EMG onset; a steeper rise of negativity called the negative slope (NS'), occurring 300 to 500 $\mathrm{ms}$ before EMG onset; and the initial slope of the movement potential (MP) occurring 50 to $100 \mathrm{~ms}$ before EMG onset. ${ }^{19-24}$ These potentials likely represent movement preparation. With simple RT movements, in which there is little movement preparation, the BP and NS' are absent and only the MP can be recorded. ${ }^{24}$ Although the precise source of different MRCPs components is still being debated, subdural recordings showed that the BP and NS' can be recorded from a relatively wide area over the contralateral precentral gyrus ${ }^{20,22,25,26}$ and bilateral supplementary motor area (SMA). ${ }^{25.27}$ In contrast, the MP appears to be generated focally from the involved motor representations in the contralateral precentral gyrus. ${ }^{20,22,24,25}$

\section{Movement-related magnetic field (MRMF) studies}

MRMFs are recorded by averaging MEG signals time-locked to movement onset, similar to MRCPs. The principal generator sources of MEG differ from that of EEG. MEG signals arise mainly from synaptic currents in the fissural cortex (tangentially oriented generators), whereas EEG and ECoG are more sensitive to radially oriented generators in the crown of cortical gyri. A slow magnetic field, known as the readiness field (RF), can be detected 0.3 to 1 second prior to movement onset ${ }^{28,29}$ Compared to the BP in MRCPs, the RF begins later and has greater 
contralateral predominance. In many subjects the RF cannot be separated into two separate components, but in some subjects there is an inflection point in the RF several hundred ms prior to movement onset which may correspond to the onset of NS' in MRCPs. ${ }^{29}$ The difference between BP, NS' and RF may be related to earlier activation of the crown of precentral gyrus preferentially recorded by EEG, and later activation of fissural cortex recorded by $\mathrm{MEG}^{29}$

\section{Event-related desynchronization (ERD) of cortical rhythms}

Rhythmic oscillation is one of the fundamental features of the human brain ${ }^{30}$ and these rhythms can be recorded by EEG or MEG. Two well-known rhythms in the 8 to $12 \mathrm{~Hz}$ range are the alpha rhythm arising from the occipital cortex and the mu rhythm recorded over the rolandic (sensorimotor) regions. The rolandic rhythm also contains $20 \mathrm{~Hz}$ components in addition to $10 \mathrm{~Hz}$ components. $\mathrm{ECoG},{ }^{31-32} \mathrm{MEG}^{33-35}$ and $\mathrm{EEG}^{36}$ studies have suggested that the $10 \mathrm{~Hz}$ rhythm is mainly generated in the somatosensory cortex while the $20 \mathrm{~Hz}$ rhythm predominantly arises from the motor cortex.

Phasic reactivity of the rolandic ECoG rhythms in response to simple voluntary movements was first described by Jasper and Penfield. ${ }^{31}$ Other investigators ${ }^{32,37}$ soon made similar observations on scalp EEG, corresponding to the well known phenomenon of blocking (desynchronization) of the rolandic mu rhythm. Further studies showed that this event-related desynchronization (ERD) begins about 1.5 seconds prior to onset of self-paced movements and likely reflects functional activation of movement-related cortical areas in preparation for movement initiation. ${ }^{20.21}$ Topographical mapping studies of scalp EEG and subdural recordings showed that ERD initially begins over the contralateral sensorimotor cortex and becomes bilateral before movement onset. ${ }^{20,21,38}$

\section{Relationship between EEG, MEG and TMS studies}

We found no increase in MEP amplitude from 500 to $100 \mathrm{~ms}$ before EMG onset (Figure 1), ${ }^{15}$ indicating that the NS' is not associated with increased motor cortex (or spinal cord) excitability. Although the time intervals we studied did not include the onset of BP or ERD which occurred much earlier than NS', it is unlikely that either BP or ERD is associated with increased motor cortex excitability, as there was no change with NS'. How can these findings be reconciled with subdural recordings ${ }^{20,22,25,26}$ which showed that the contralateral precentral gyrus is involved in generating BP, NS' and ERD? TMS stimulates corticospinal neurons in layer $\mathrm{V}$ of the motor cortex directly and indirectly via cortical interneurons. ${ }^{39-41}$ EEG and MEG potentials reflect current changes in the apical dendrites of all pyramidal cells, not only the corticospinal neurons. Thus, there could be functional differences between the superficial and deep pyramidal neurons. The motor cortex involvement in movement preparation, as demonstrated by $\mathrm{BP}, \mathrm{NS}$ ' and $\mathrm{ERD}$, are apparently related to motor cortex circuits that are active before the activation of the corticospinal system. Inputs from the SMA or premotor cortex to the motor cortex, or activities of intrinsic cortical circuits in the motor cortex may underlie the components of BP, NS' and ERD generated from the precentral gyrus.

The timing of the premovement increased cortical excitability corresponds well with that of the onset of the MP. This supports the hypothesis that the initial slope of the MP arises from

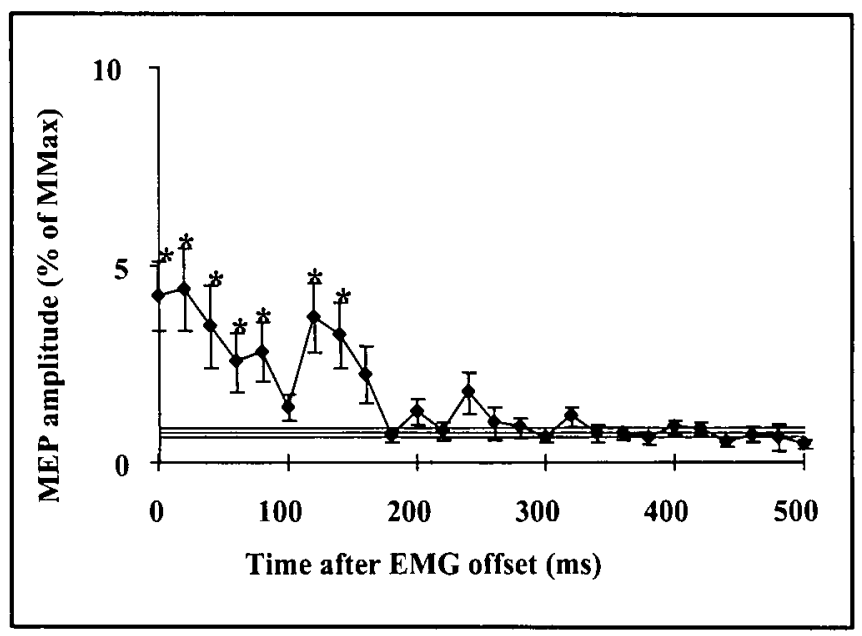

Figure 2: Period of increased corticospinal excitability after voluntary movements. Results from six subjects performing self-paced movements. Simple reaction time movements showed similar results. Subthreshold transcranial magnetic stimulation was applied at different times after EMG offset. There were two phases of increased corticospinal excitability, the first phase 0 to $100 \mathrm{~ms}$ and second phase from 100 to $160 \mathrm{~ms}$ after EMG offset. The abbreviations and notations are identical to those for Figure 1. Modified from Chen et al. ${ }^{15}$

the motor cortex ${ }^{20.22 .24}$ and suggests that the MP is associated with increased excitability of corticospinal neurons.

\section{Postmovement Increase in Motor Cortex Excitability}

\section{Transcranial magnetic stimulation (TMS) studies}

Corticospinal excitability after voluntary movements has not been extensively studied. We used TMS to examine the time course of corticospinal excitability after simple RT and self-paced movements, ${ }^{15}$ and found increased corticospinal excitability in the first $160 \mathrm{~ms}$ after EMG offset. This increased corticospinal excitability appears to consist of two phases. The first phase ranges from 0 to approximately $100 \mathrm{~ms}$, and the second phase from approximately 100 to $160 \mathrm{~ms}$ after EMG offset (Figure 2). ${ }^{15}$

The first phase of increased corticospinal excitability probably represents the time when the decreasing output from the motor cortex falls below that required to activate spinal motoneurons, leading to cessation of EMG, but the activity of motor cortex neurons remains above baseline levels. This is consistent with recordings from the monkey motor cortex that many neurons continue to discharge after EMG offset. ${ }^{4,8,9}$

The second phase of postmovement increased corticospinal excitability from about 100 to $160 \mathrm{~ms}$ after EMG offset may be due to sensory feedback from passive movement of the thumb. Accelerometer recordings showed that thumb movements continued for 200 to $400 \mathrm{~ms}$ after EMG offset. ${ }^{15}$ In the monkey motor cortex, many neurons can be activated by passive movement of the contralateral $\mathrm{arm}^{7}$ and cutaneous stimulation of the glabrous skin of the hand, ${ }^{42}$ suggesting that proprioceptive and cutaneous inputs can increase motor cortex excitability. ${ }^{43}$ Another explanation for the second phase of postmovement increased corticospinal excitability is that it is centrally programmed and relates to a subthreshold, second agonist burst. While a triphasic agonist-antagonist-agonist pattern of muscle 
activity is usually observed in movements where a target position is specified, ${ }^{44-46}$ we found only a single agonist burst with the simple thumb abduction movement. ${ }^{15}$ The absence of the antagonist and the second agonist burst is similar to previous studies of thumb movements, $, 7,48$ and is probably due to the low inertial load and that the antagonist burst was not necessary because the target position was not specified. ${ }^{48-49}$ The timing of the second phase of postmovement increased corticospinal excitability is similar to that of the second agonist burst for thumb flexion ${ }^{45}$ and elbow flexion ${ }^{44}$ movements. Thus, the second phase of postmovement increased corticospinal excitability may represent increased activity of corticospinal neurons related to the second agonist burst, which remained subthreshold for activation of spinal motorneurons. Our findings are consistent with the suggestion that the triphasic pattern is centrally programmed. ${ }^{44,45,50}$

\section{Movement-related cortical potential (MRCP) studies}

MRCP studies showed several peaks after EMG onset, which likely represent activation of different cortical areas. ${ }^{23,24}$ These include the parietal peak of motor potential (ppMP), which reaches its maximum amplitude over the contralateral central-parietal scalp regions 20 to $50 \mathrm{~ms}$ after EMG onset. The ppMP occurs during the EMG burst and may represent the terminal phase of motor cortex firing to execute movement. The ppMP is followed by the frontal peak of motor potential (fpMP), occurring about $100 \mathrm{~ms}$ after EMG onset. With EMG burst durations around $100 \mathrm{~ms},{ }^{15}$ the fpMP approximately corresponds to the time of EMG offset.

In addition to conventional MRCPs related to movement onset, MRCPs related to muscle relaxation can be recorded by averaging EEG signals time-locked to EMG offset. ${ }^{51.52}$ The motor cortex appears to be active before muscle relaxation in tasks that require active suppression of muscle activity (active relaxation), but there appears to be no significant motor cortex activity before tasks that require only withdrawal of tonic input. ${ }^{52}$ Following both active and passive muscle relaxation, there is a postrelaxation MRCP peak occurring about $120 \mathrm{~ms}$ after EMG offset. ${ }^{52}$

\section{Movement-related magnetic field (MRMF) studies}

MRMFs also showed several peaks after the onset of voluntary movements. ${ }^{28.29}$ The motor field (MF), which peaks around $30 \mathrm{~ms}$ after EMG onset, is probably similar to the ppMP in MRCP studies. The movement-evoked magnetic field (MEFI), occurring 100 to $150 \mathrm{~ms}$ after EMG onset, is likely analogous to the fpMP in MRCP studies. The MEFI is followed by the MEFII, occurring 200 to $250 \mathrm{~ms}$ after EMG onset. Topographic mapping studies suggested that the MRMFs originate predominantly from the contralateral sensorimotor cortex. ${ }^{28-29}$

\section{Event-related desynchronization (ERD) studies}

ERD of the cortical rhythm over the sensorimotor cortex that began about 1.5 seconds prior to movement continues for 0.75 to 2 seconds after movement onset. ${ }^{33,34,38}$ ERD is followed by a period of increased power above baseline levels, known as eventrelated synchronization (ERS). ${ }^{33,34,36,38,53}$

\section{Relationship between EEG, MEG and TMS studies}

The timing of the first phase of postmovement increased cortical excitability is similar to that of the fpMP in MRCPs studies and the MEFI in MEG studies. The fpMP and MEFI occur about 100 to $150 \mathrm{~ms}$ after EMG onset. With EMG burst durations around $100 \mathrm{~ms},{ }^{15}$ this corresponds to about 0 to $50 \mathrm{~ms}$ after movement offset, similar to the timing of the first phase of postmovement increased cortical excitability. Similarly, the timing of the MEFII (200 to $250 \mathrm{~ms}$ after EMG onset) approximates that of the second phase of postmovement increased cortical excitability (100 to $160 \mathrm{~ms}$ after EMG offset). However, there are differences in the paradigms in our TMS study and those used in MRCP and MRMF studies. Further studies are necessary to clarify whether the postmovement increased corticospinal excitability periods correspond to fpMP, MEFI and MEFII.

\section{Postmovement Decrease in Corticospinal Excitability}

\section{Transcranial magnetic stimulation (TMS) studies}

We used TMS to examine corticospinal excitability up to 4 seconds after EMG offset. ${ }^{15}$ The stimulus intensity was adjusted to produce MEPs of about $1 \mathrm{mV}$ in amplitude. Compared to subthreshold TMS, the suprathreshold TMS produced more variable baseline but enabled us to detect both increased and decreased corticospinal excitability, whereas subthreshold TMS can only detect increased corticospinal excitability. For both RT and selfpaced movements, we found decreased corticospinal excitability from about 500 to 1,000 ms after EMG offset (Figure 3). ${ }^{15}$

\section{Event-related synchronization (ERS) studies}

The rhythm of the sensorimotor cortex consists of $10 \mathrm{~Hz}$ and $20 \mathrm{~Hz}$ components. The timing of the ERD and ERS differs depending on the frequency band. ERS of the $20 \mathrm{~Hz}$ EEG begins about $750 \mathrm{~ms}$ after EMG onset. ${ }^{36,38,54}$ ERS of the $10 \mathrm{~Hz}$ EEG occurs later at about 2 seconds after EMG onset. ${ }^{36,38}$ MEG studies also showed similar findings with increased 10 and $20 \mathrm{~Hz}$ activities after self-paced movements, ${ }^{33,34}$ and the increase in 20 $\mathrm{Hz}$ activity precedes the increase in $10 \mathrm{~Hz}$ activity by about 300 ms. Since the $10 \mathrm{~Hz}$ rhythm is mainly generated in the somatosensory cortex while the $20 \mathrm{~Hz}$ rhythm predominantly arises from the motor cortex, ${ }^{31-36}$ ERS of the motor cortex occurs earlier than that of the somatosensory cortex.

\section{Relationship between TMS and ERS studies}

The timing of the postmovement decrease in corticospinal excitability is similar to the onset of ERS of the $20 \mathrm{~Hz}$ cortical rhythm in EEG and MEG studies, which likely originates from the motor cortex. ${ }^{33,34,36,55}$ It has been suggested that while ERD represents cortical activation, ERS represents an inactive, idling state of the cortex with reduced excitability ${ }^{36,53}$ or increased inhibition. ${ }^{33}$ ERS may therefore be an electrophysiological correlate of deactivated cortical areas. ${ }^{34,36,53}$ Supporting evidence for this hypothesis includes the occurrence of ERS in cortical areas not involved in processing of sensory information or motor output. For example, enhancement of the mu rhythm of the primary hand area occurs during visual processing or during foot movement. ${ }^{36}$ The postmovement ERS has been suggested to represent deactivation of the sensorimotor cortex following activation. ${ }^{34,36,53}$ Our finding of reduced corticospinal excitability at the time of onset of ERS supports this hypothesis.

\section{Effects of Sensory Stimulation on Motor Cortex EXCITABILITY}

Additional support for the hypothesis that ERS represents decreased cortical excitability comes from studies on the effects 


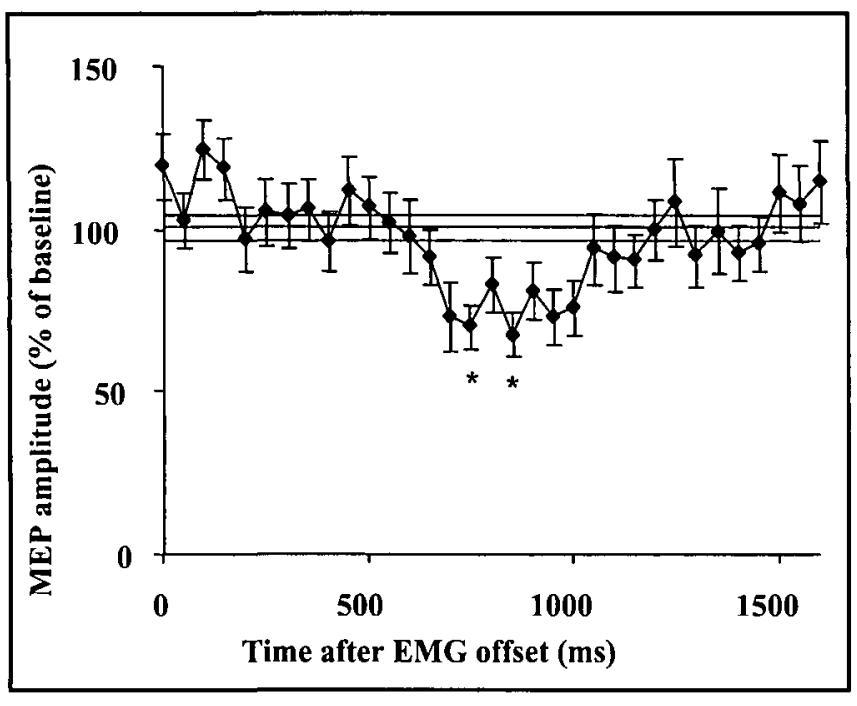

Figure 3: Period of decreased corticospinal excitability after voluntary movements. Results from six subjects performing simple reaction time movements. Self-paced movements showed similar results. Suprathreshold transcranial magnetic stimulation was applied at different times after EMG offset. The corticospinal excitability was decreased from about 650 to 1,000 ms after EMG offset. The abbreviations and notations are identical to those for Figure 1. Modified from Chen et al. ${ }^{15}$

of sensory input. The activity of pyramidal neurons in monkey motor cortex changes in response to peripheral stimulation. ${ }^{56-58}$ In humans, median nerve stimulation leads to an immediate decrease in the $20 \mathrm{~Hz}$ rolandic MEG rhythm (ERD). This is followed by increased activity above the baseline level (ERS), which begins about $200 \mathrm{~ms}$ after median nerve stimulation, peaks around 400 to $500 \mathrm{~ms}$ and lasts about $1,000 \mathrm{~ms}{ }^{33,59,60}$ The rebound in $20 \mathrm{~Hz}$ activity following median nerve stimulation is decreased by activation of the motor cortex with voluntary movement, motor imagery or tactile stimulation of the hand..$^{59,60}$ Rebound of the $20 \mathrm{~Hz}$ rhythm also occurs in the ipsilateral motor cortex following median nerve stimulation, but is of lower amplitude and slightly shorter latency than that of the changes in the contralateral motor cortex..$^{59,60}$

We used TMS to study the changes in motor cortex excitability following median nerve stimulation, and found reduced excitability of the contralateral motor cortex from 200 to $1,000 \mathrm{~ms}$ after median nerve stimulation. ${ }^{61}$ The excitability of the motor cortex ipsilateral to median nerve stimulation was also decreased, but the reduction was less than that of the contralateral motor cortex and was of shorter duration. ${ }^{61}$ Thus, the timing of decreased motor cortex excitability following median nerve stimulation corresponds well with that of the increase in the $20 \mathrm{~Hz}$ MEG rhythm, supporting the hypothesis that ERS represents reduced cortical excitability.

\section{Abnormalities of Cortical Activation in Movement DISORDERS}

The time course of motor cortex excitability associated with voluntary movement may be a useful way to study the pathophysiology of movement disorders. We will describe here briefly the findings in Parkinson's disease (PD) and dystonia.

\section{Parkinson's disease}

The clinical finding of akinesia in PD patients is reflected in prolonged RTs. TMS studies showed that the premovement build up of motor cortex excitability in simple RT tasks is slower in PD patients compared to controls. ${ }^{62}$ The increase in motor cortex excitability begins about $140 \mathrm{~ms}$ before EMG onset in PD patients compared to about $80 \mathrm{~ms}$ before EMG onset in normal subjects. ${ }^{62}$ The time course of motor cortex excitability for selfpaced movements in PD patients has not been studied. Since PD patients have more difficulty with self-paced movements than externally triggered movements, ${ }^{62-67}$ the premovement build up in cortical excitability may be even more abnormal in self-paced than simple RT movements. Several MRCPs studies showed reduced $\mathrm{BP}$ and NS' before self-paced movement ${ }^{63,68,69}$ and with imagination of movement ${ }^{70}$ in PD patients, suggesting that movement preparation is deficient. However, some studies found no abnormality in the MRCPs in PD patients. ${ }^{71.72}$ These different results are likely related to whether the patients were on antiparkinsonian medications and variations in the motor paradigms used. Dopaminergic medications can normalize MRCPs in PD patients. ${ }^{68}$ Most of the studies that reported reduction in MRCPs were performed after withdrawal of antiparkinsonian medications, ${ }^{63.68}$ whereas studies that found normal MRCPs were performed with patients on antiparkinsonian medications. ${ }^{71.72}$ The rate of decline in MRCP amplitudes following voluntary movement was reduced in PD patients compared to controls, ${ }^{73}$ suggesting that termination of movement is also impaired and motor cortex excitability following movement may be abnormal.

ERD and ERS are also abnormal in PD patients. ERD prior to and during voluntary movements is reduced in PD patients and improved with levodopa ${ }^{74,75}$ These findings are consistent with the hypothesis of Brown and Marsden ${ }^{76}$ that the function of the basal ganglia is to release cortical elements from idling (10 and $20 \mathrm{~Hz}$ ) rhythms. ERS for the $20 \mathrm{~Hz}$ (beta) band EEG was found to be much smaller for PD patients compared to normal subjects, and it has been suggested that this is related to impaired recovery of primary motor area after movement. ${ }^{77}$ Therefore, the postmovement decrease in corticospinal excitability may also be abnormal in PD patients.

\section{Dystonia}

The NS' component of MRCPs is reduced in patients with writer's cramp ${ }^{78}$ and idiopathic torsion dystonia, ${ }^{79}$ but the $\mathrm{BP}$ and fpMP were found to be normal. Compared to PD patients, the abnormalities in dystonia patients were limited to a segment of the NS' (300 to $200 \mathrm{~ms}$ prior to EMG onset) ${ }^{78}$ whereas in PD patients the BP and the entire length of the NS' were abnormal. ${ }^{68}$ The NS' abnormalities in dystonia were restricted to electrodes overlying the contralateral and midline central electrodes ${ }^{78}$ whereas the abnormalities in PD were more widespread ${ }^{68}$ There is also reduced ERD prior to movement over the contralateral central region in writer's cramp patients. ${ }^{80}$ These studies suggest that motor activation is abnormal prior to simple voluntary movements in patients with dystonia.

\section{Conclusions}

Studies with TMS, EEG and MEG show that there are a series of changes in the excitability of the human motor cortex before and after voluntary movements. The premovement changes likely represent movement preparation. The postmovement modulations may reflect centrally programmed patterns of movement, 
sensory feedback and changes necessary to deactivate the motor cortex to return it the resting state. The time course of motor cortex excitability changes are abnormal in patients with disorders of movement, such as Parkinson's disease and dystonia.

\section{ACKNOWLEDGEMENTS}

Supported by the National Institute of Neurological Disorders and Stroke Intramural Program, the Medical Research Council of Canada (grant no. MT-15128, RC) and the University Health Network Krembil Family Chair in Neurology. RC is a Medical Research Council of Canada Scholar.

\section{REFERENCES}

1. Jackson JH. On the comparative study of diseases of the nervous system. Brit Med J 1889; 355-362.

2. Leyton ASF, Sherrington CS. Observations on the excitable cortex of the chimpanzee, orangutan, and gorilla. Q J Exp Physiol 1917; 11: 135-222.

3. Penfield W, Jasper H. Epilepsy and the Functional Anatomy of the Human Brain. Boston: Little, Brown, 1954.

4. Evarts EV. Pyramidal tract activity associated with a conditional hand movement in the monkey. J Neurophysiol 1966; 29: 10111027.

5. Luschei ES, Johnson RA, Glickstein M. Response of neurones in the motor cortex during performance of a simple repetitive arm movement. Nature 1968; 217: 190-191.

6. Godschalk M, Lemon RN, Nijs HGT, Kuypers HGJM. Behaviour of neurones in monkeys periarcuate and precentral cortex before and during visually guided arm and hand movements. Exp Brain Res 1981; 44: 113-116.

7. Fetz EE, Finocchio DV. Operant conditioning of specific patterns of neural and muscular activity. Science $1971 ; 174: 431-435$.

8. Riehle A, Requin J. Monkey primary motor and premotor cortex: single-cell activity related to prior information about direction and extent of an intended movement. J Neurophysiol 1989; 61: 534-549.

9. Thach WT. Timing of activity in cerebellar dentate nucleus and cerebral motor cortex during prompt volitional movement. Brain Res 1975; 88: 233-241.

10. Starr A, Caramia M, Zarola F, Rossini PM. Enhancement of motor cortical excitability in humans by non-invasive electrical stimulation appears prior to voluntary movement. Electroencephalogr Clin Neurophysiol 1988; 70: 26-32.

11. Rossini PM, Zarola F, Stalberg E, Caramia M. Pre-movement facilitation of motor-evoked potentials in man during transcranial stimulation of the central motor pathways. Brain Res 1988; 458: 20-30.

12. Pascual-Leone A, Valls-Solé J, Wassermann EM, et al. Effects of focal transcranial magnetic stimulation on simple reaction time to acoustic, visual and somatosensory stimuli. Brain 1992; 115: 1045-1059.

13. Tomberg C, Caramia MD. Prime mover muscle in finger lift or finger flexion reaction times: identification with transcranial magnetic stimulation. Electroencephalogr Clin Neurophysiol 1991; 81: 319-322.

14. Hoshiyama M, Kitamura Y, Koyama S, et al. Reciprocal change of motor evoked potentials preceding voluntary movements in humans. Muscle Nerve 1996; 19: 125-131.

15. Chen R, Yaseen Z, Cohen LG, Hallett M. The time course of corticospinal excitability in reaction time and self-paced movements. Ann Neurol 1998; 44: 317-325.

16. Gottlieb GL, Agarwal GC, Stark L. Interactions between voluntary and postural mechanisms of the human motor system. J Physiol (Lond) 1970; 33: 365-381.

17. Pierrot-Deseilligny E, Lacert $P$, Cathala HP. Amplitude et variabilité des réflexes monosynaptiques avant un mouvement volontaire. Physiol Behav 1971; 7: 495-508.
18. Eichenberger A, Rüegg DG. Relation between the specific $\mathrm{H}$ reflex activation preceding a voluntary movement and movement parameters in man. J Physiol (Lond) 1984; 347: 545-559.

19. Deecke L, Scheid P, Kornhuber HH. Distribution of readiness potential, pre-motion positivity, and motor potential of the human cerebral cortex preceding voluntary finger movements. Exp Brain Res 1969; 7: 158-168.

20. Toro C, Deuschl G, Thatcher R, et al. Event-related desynchronization and movement-related cortical potentials on the ECoG and EEG. Electroencephalogr Clin Neurophysiol 1994; 93: 380-389.

21. Pfurtscheller G, Aranibar A. Event-related desynchronization detected by power measurements of scalp EEG. Electroencephalogr Clin Neurophysiol 1989; 72: 250-258.

22. Neshige R, Lüders $H$, Shibasaki H. Recording of movement-related potentials from scalp and cortex in man. Brain 1988; 111: 719 736.

23. Shibasaki H, Barrett G, Halliday E, Halliday AM. Components of the movement-related cortical potential and their scalp topography. Electroencephalogr Clin Neurophysiol 1980; 49: 213-226.

24. Tarkka IM, Hallett M. Topography of scalp-recorded motor potentials in human finger movements. J Clin Neurophysiol 1991; 8: $331-341$.

25. Rektor I, Fève A, Buser $\mathbf{P}$, Bathien N, Lamarche $\mathrm{M}$. Intracerebral recording of movement related readiness potentials: an exploration in epileptic patients. Electroencephalogr Clin Neurophysiol 1994; 90: 273-283.

26. Neshige R, Lüders H, Friedman L, Shibasaki H. Recording of movement-related potentials from the human cortex. Ann Neurol 1988; 24: 439-445.

27. Ikeda A, Lüders HO, Burgress RC, Shibasaki H. Movement-related potentials recorded from supplementary motor area and primary motor area. Role of supplementary motor area in voluntary movements. Brain 1992; 115: 1017-1043.

28. Nagamine T, Toro C, Balish M, Deuschl G, Wang B. Cortical magnetic and electric fields associated with voluntary finger movements. Brain Topography 1994; 6: 175-183.

29. Nagamine T, Kajola M, Salmelin R, Shibasaki H, Hari R. Movement-related slow cortical magnetic fields and changes of spontaneous MEG- and EEG-brain rhythms. Electroencephalogr Clin Neurophysiol 1996; 99: 274-286.

30. Llinas RR. The intrinsic electrophysiological properties of mammalian neurons: insights into central nervous system function. Science 1988; 242: 1654-1664.

31. Jasper H, Penfield W. Electrocorticograms in man: effect of voluntary movement upon the electrical activity of the precentral gyrus. Arch Psychiatrie Zeitschr Neurol 1949; 183: 163-174.

32. Gastaut H, Terzian H, Gastaut Y. Etude d'une activité électroencéphalographique méconnue: "Le rhythme rolandique en arceau". Marseille Med 1952; 89: 296-310.

33. Salmelin R, Hari R. Spatiotemporal characteristics of sensorimotor neuromagnetic rhythms related to thumb movement. Neuroscience 1994; 60: 537-550.

34. Salmelin R, Hämäläinen M, Kajola M, Hari R. Functional segregation of movement-related rhythmic activity in the human brain. Neuroimage 1995; 2: 237-243.

35. Salenius S, Portin K, Kajola M, Salmelin R, Hari R. Cortical control of human motoneuron firing during isometric contraction. J Neurophysiol 1997; 77: 3401-3405.

36. Pfurtscheller G, Stancák Jr. A, Neuper C. Post-movement beta synchronization. A correlate of an idling motor area? Electroencephalogr Clin Neurophysiol 1996; 98: 281-293.

37. Chatrian GE, Petersen MC, Lazarte JA. The blocking of the rolandic wicket rhythm and some central changes related to movement. Electroencephalogr Clin Neurophysiol 1959; 11: 497-510.

38. Leocani L, Toro C, Manganotti P, Zhuang P, Hallett M. Event-related coherence and event-related desynchronization/synchronization in the $10 \mathrm{~Hz}$ and $20 \mathrm{~Hz}$ EEG during self-paced movements. Electroencephalogr Clin Neurophysiol 1997; 104: 199-206.

39. Amassian VE, Quirk GJ, Stewart M. A comparison of corticospinal activation by magnetic coil and electrical stimulation of monkey motor cortex. Electroencephalogr Clin Neurophysiol 1990; 77: $390-401$. 
40. Rothwell JC, Thompson PD, Day BL, Boyd S, Marsden CD. Stimulation of the human motor cortex through the scalp. Exp Physiol 1991; 76: 159-200.

41. Nakamura $H$, Kitagawa $H$, Kawaguchi $Y$, Tsuji $H$. Direct and indirect activation of human corticospinal neurons by transcranial magnetic and electrical stimulation. Neurosci Lett 1996; $210: 45-$ 48.

42. Picard N, Smith GA. Primary motor cortical activity related to the weight and texture of grasped objects in the monkey. $J$ Neurophysiol 1992; 68: 1867-1881.

43. Fetz EE, Baker MA. Operantly conditioned patterns of precentral unit activity and correlated responses in adjacent cells and contralateral muscles. J Neurophysiol 1973; 36: 179-204.

44. Hallett M, Shahani BT, Young RR. EMG analysis of stereotyped voluntary movements in man. J Neurol Neurosurg Psychiatry 1975; 38: 1154-1162.

45. Hallett $M$, Marsden $C D$. Ballistic flexion movements of the human thumb. J Physiol (Lond) 1979; 294: 33-50.

46. Brown SHC, Cooke JD. Amplitude- and instruction-dependent modulation of movement-related electromyogram activity in humans. J Physiol (Lond) 1981; 316: 97-107.

47. Marsden CD, Obeso JA, Rothwell JC. The function of the antagonist muscle during fast limb movements in man. J Physiol (Lond) 1983; 335: 1-13.

48. Menick HM, Benecke R, Meyer W, Hohne J, Conrad B. Human ballistic finger flexion: uncoupling of the three-burst pattern. Exp Brain Res 1984; 55: 127-133.

49. Lestienne F. Effects of inertial load and velocity on the braking process of voluntary limb movements. Exp Brain Res 1979; 35: 407-418.

50. Sanes JN, Jennings VA. Centrally programmed patterns of muscle activity in voluntary motor behavior of humans. Exp Brain Res 1984; 54: 23-32.

51. Terada K, Ikeda A, Nagamine T, Shibasaki H. Movement-related cortical potentials associated with voluntary muscle relaxation. Electroencephalogr Clin Neurophysiol 1995; 95: 335-345.

52. Rothwell JC, Higuchi K, Obeso JA. The offset cortical potential: an electrical correlate of movement inhibition in man. Mov Disord 1998; 13: 330-335.

53. Pfurtscheller G. Event-related synchronization (ERS): an electrophysiological correlate of cortical areas at rest. Electroencephalogr Clin Neurophysiol 1992; 83: 62-69.

54. Stancák Jr. A, Pfurtscheller G. Desynchronization and recovery of $\beta$ rhythms during brisk and slow self-paced finger movements in man. Neurosci Lett 1995; 196: 21-24.

55. Hari R, Salmelin R. Human cortical oscillations: a neuromagnetic view through the skull. Trends Neurosci 1997; 20: 44-49.

56. Evarts EV. Motor cortex reflexes associated with learned movement. Science 1973; 179: 501-503.

57. Wiesendanger $M$. Input from muscle and cutaneous nerves of the hand and forearm to neurons of the precentral gyrus of baboons and monkeys. J Physiol (Lond) 1973; 228: 203-219.

58. Porter R, Rack PM. Timing of responses in the motor cortex monkeys to an unexpected disturbance of finger position. Brain Res 1976; 103: 201-213.

59. Salenius S, Schnitzler A, Salmelin R, Jousmäki V, Hari R. Modulation of human cortical rolandic rhythms during natural sensorimotor tasks. Neuroimage 1997; 5: 221-228.

60. Schnitzler A, Salenius S, Salmelin R, Jousmäki V, Hari R. Involvement of primary motor cortex in motor imagery: a neuromagnetic study. Neuroimage 1997; 6: 201-208.

61. Chen R, Corwell B, Cohen LG, Hallett M. Reduction of motor cortex excitability after median nerve stimulation. Muscle Nerve 1998; 21 : 1585. (Abstract).
62. Pascual-Leone A, Valls-Solé J, Brasil-Neto JP, Cohen LG, Hallett M. Akinesia in Parkinson's disease. 1. Shortening of simple reaction time with focal, single-pulse transcranial magnetic stimulation. Neurology 1994; 44: 884-891.

63. Jahanshahi $M$, Jenkins IH, Brown RG, et al. Self-initiated versus externally triggered movements. I. An investigation using measurement of regional cerebral blood flow with PET and movement-related potentials in normal and Parkinson's disease subjects. Brain 1995; 118: 913-933.

64. Marsden CD. Slowness of movement in Parkinson's disease. Mov Disord 1989; 4 (Suppl. 1): S26-S37.

65. Dietz MA, Goetz CG, Stebbins GT. Evaluation of a modified inverted walking stick as a treatment for parkinsonian freezing episodes. Mov Disord 1990; 5: 243-247.

66. Benecke R, Rothwell JC, Dick JP, Day BR, Marsden CD Performance of simultaneous movements in patients with Parkinson's disease. Brain 1986; 109: 739-757.

67. Benecke R, Rothwell JC, Dick JP, Day BR, Marsden CD. Disturbance of sequential movements in patients with Parkinson's disease. Brain 1987; 110: 361-379.

68. Dick JPR, Rothwell JC, Day BL, et al. The Bereitshaftspotential is abnormal in Parkinson's disease. Brain 1989; 112: 233-244.

69. Samuel M, Ceballos-Baumann AO, Blin J, et al. Evidence for lateral premotor and parietal overactivity in Parkinson's disease during sequential and bimanual movements. A PET study. Brain 1997; 120: 963-976.

70. Cunnington R, Iansek R, Johnson KA, Bradshaw JL. Movementrelated potentials in Parkinson's disease. Motor imagery and movement preparation. Brain 1997; 120: 1339-1353.

71. Defebvre L, Bourriez JL, Dujardin K, et al. Spatiotemporal study of Bereitschaftspotential and event-related desynchronization during voluntary movement in Parkinson's disease. Brain Topography 1994; 6: 237-244.

72. Ikeda A, Kaji R, Terada $K$, et al. Dissociation between contingent negative variation (CNV) and Bereitschaftspotential (BP) in patients with parkinsonism. Electroencephalogr Clin Neurophysiol 1997; 102: 142-151.

73. Cunnington R, Iansek R, Bradshaw JL, Phillips JG. Movement-related potentials in Parkinson's disease. Presence and predictability of temporal and spatial cues. Brain 1995; 118: 935-950.

74. Brown P, Marsden CD. EEG desynchronization during movement and bradykinesia in Parkinson's disease. Mov Disord 1998; 13 (Suppl. 2): 57 (Abstract).

75. Wang HC, Lees AJ, Brown P. EEG desynchronization prior to movement and bradykinesia in Parkinson's disease. Mov Disord 1998; 13 (Suppl. 2): 35 (Abstract).

76. Brown $\mathrm{P}$, Marsden CD. What do the basal ganglia do? Lancet 1998; 351: 1801-1804.

77. Pfurtscheller G, Pichler-Zalaudek K, Ortmayr B, Diez J, Reisecker F. Postmovement beta synchronization in patients with Parkinson's disease. J Clin Neurophysiol 1998; 15: 243-250.

78. Deuschl G, Toro C, Matsumoto J, Hallett M. Movement-related cortical potentials in writer's cramp. Ann Neurol 1995; 38: 862-868.

79. Van Der Kamp W, Rothwell JC, Thompson PD, Day BL, Marsden $\mathrm{CD}$. The movement-related cortical potential is abnormal in patients with idiopathic torsion dystonia. Mov Disord 1995; 10: 630-633

80. Toro C, Deuschl G, Hallett M. Movement-related EEG desynchronization in patients with hand cramps: evidence for cortical involvement in hand cramps. Neurology 1998; 43: A379 (Abstract) 